\title{
Connexin43 Mediates Direct Intercellular Communication in Human Osteoblastic Cell Networks
}

\author{
Roberto Civitelli, Eric C. Beyer, * Pamela M. Warlow, Audra J. Robertson, ${ }^{\star}$ Steven T. Geist, ${ }^{\star}$ and Thomas H. Steinberg ${ }^{\ddagger}$ \\ Division of Endocrinology and Bone and Mineral Diseases, the Jewish Hospital of St. Louis; * Divisions of Hematology/Oncology, and \\ ${ }^{\ddagger}$ Infectious Diseases; Departments of Medicine, Pediatrics, and Cell Biology and Physiology, \\ Washington University School of Medicine, St. Louis, Missouri 63110
}

\begin{abstract}
We have examined cell coupling and expression of gap junction proteins in monolayer cultures of cells derived from human bone marrow stromal cells (BMC) and trabecular bone osteoblasts (HOB), and in the human osteogenic sarcoma cell line, SaOS-2. Both HOB and BMC cells were functionally coupled, since microinjection of Lucifer yellow resulted in dye transfer to neighboring cells, with averages of $3.4 \pm 2.8(n=131)$ and 8.1 $\pm 9.3(n=51)$ coupled cells per injection, respectively. In contrast, little diffusion of Lucifer yellow was observed in SaOS-2 monolayers (1.4 \pm 1.8 coupled cells per injection, $n$ $=100)$. Dye diffusion was inhibited by octanol $(3.8 \mathrm{mM})$, an inhibitor of gap junctional communication. All of the osteoblastic cells expressed mRNA for connexin 43 and connexin 45 , but not for connexins $26,32,37,40$, or 46 . Whereas all of the osteoblastic cells expressed similar quantities of mRNA for connexin 43 , the poorly coupled SaOS-2 cells produced significantly less $\mathrm{Cx} 43$ protein than either $\mathrm{HOB}$ or BMC, as assessed by immunofluorescence and immunoprecipitation. Conversely, more Cx45 mRNA was expressed by SaOS-2 cells than by HOB or BMC. Thus, intercellular coupling in normal and transformed human osteoblastic cells correlates with the level of expression of $\mathrm{Cx} 43$, which appears to mediate intercellular communication in these cells. Gap junctional communication may serve as a means by which osteoblasts can work in synchrony and propagate locally generated signals throughout the skeletal tissue. ( J. Clin. Invest. 1993. 91:1888-1896.) Key words: gap junctions • connexins • osteoblasts • dye-coupling • cell-cell communication
\end{abstract}

\section{Introduction}

Bone remodeling is the result of a complex and coordinated series of events occurring in the skeletal tissue. These processes include sequential degradation of bone matrix and dissolution of the mineral phase (bone resorption), followed by deposition of new bone matrix and mineralization (bone formation) ( 1 , 2 ). This organized pattern of events requires a coordinated

Portions of this work were presented at the 13th annual meeting of the American Society for Bone and Mineral Research, 24-28 August 1991, San Diego, CA, and have appeared in abstract form (No. 672).

Address correspondence to Roberto Civitelli, M. D., Division of Bone and Mineral Diseases, The Jewish Hospital of St. Louis, $216 \mathrm{~S}$. Kingshighway Boulevard, St. Louis, MO 63110.

Received for publication 19 October 1992 and in revised form 28 December 1992.

J. Clin. Invest.

(C) The American Society for Clinical Investigation, Inc.

0021-9738/93/05/1888/09 \$2.00

Volume 91, May 1993, 1888-1896 action by the cells of bone: osteoblasts, osteoclasts, and osteocytes (3). Cells of the osteoblastic lineage are pivotal to bone remodeling, since most, if not all, chemical, mechanical, and probably electrical stimuli are processed by these cells. Not only are the osteoblasts directly involved in bone formation, but they also function as transmitters of bone resorptive signals to the osteoclast (4). In fact osteoblasts, rather than osteoclasts, express receptors for hormones with bone resorptive activity, such as parathyroid hormone, parathyroid hormone-related peptide, and 1,25-dihydroxy-cholecalciferol (5-7).

This coordinated activity among bone cells implies the existence of intercellular communication, but its mechanisms are not well characterized. Intercellular communication may occur via secretion of soluble factors, direct cell-cell contact through cell adhesion/recognition molecules, or by metabolic and electric coupling through gap junctions. There is evidence that osteoblastic cells secrete soluble factors when they are stimulated by hormones or cytokines, and that these factors may transmit the resorptive signal from osteoblasts to osteoclasts (8-12). However, no specific factor has been isolated or characterized to date. In contrast, the presence of gap junctions between osteoblasts has been documented morphologically in sections of normal bone (13-15), and in rat calvaria cells in culture (16). These gap junctions have been observed between adjacent osteoblasts, osteoblasts and periosteal fibroblasts, and osteoblasts and osteocytic processes in sections of normal bone (13-15). Recently, the gap junction protein connexin43 $(\mathrm{Cx} 43)^{1}$ has been identified in normal and transformed rat osteoblastic cells $(17,18)$.

In the present study, we have characterized gap junction communication in human bone-derived osteoblastic cells and in a human osteogenic sarcoma cell line. We found that $\mathrm{Cx} 43$, originally identified from rat heart, appears to be the protein that mediates gap junction communication in human osteoblastic cells. Another gap junction protein, $\mathrm{Cx} 45$, was identified in these cells, but its expression does not correlate with dye coupling.

\section{Methods}

Reagents and chemicals

Lucifer yellow was purchased from Molecular Probes (Eugene, OR). The stock was dissolved in distilled, deionized water, to a $10-\mathrm{mM}$ concentration, and stored at $-20^{\circ} \mathrm{C}$ in the dark. $\left[{ }^{35} \mathrm{~S}\right]$ trans-S was obtained from ICN Biomedicals (Boston, MA). Polyclonal rabbit antiserum directed against connexin 43 was produced by immunizing rabbits with a synthetic peptide (252-271 fragment of rat connexin43) (19). Rabbit polyclonal antiserum against $\mathrm{Cx} 45$ was similarly generated using an oligopeptide corresponding to amino acids 285-298 of dog Cx45 (20).

1. Abbreviations used in this paper: BMC, bone marrow osteogenic stromal cells; $\mathrm{Cx}$, connexin; $\mathrm{HOB}$, human trabecular osteoblasts. 
All other chemicals and the tissue culture media were from Sigma Chemical Co. (St. Louis, MO), unless otherwise indicated. Octanol, an inhibitor of gap junction communication, was used to confirm that dye transfer was mediated by gap junctions. Octanol dilutions were prepared fresh, before use, following a procedure described by Musil et al. (21). Briefly, $20 \mu \mathrm{l}$ of a 1:4 solution of octanol in ethanol were added to $10 \mathrm{ml}$ of culture medium (see below) at $37^{\circ} \mathrm{C}$, and vortexed vigorously for $2 \mathrm{~min}$ to ensure proper dissolution. This procedure yields final concentrations of $3.8 \mathrm{mM}$ octanol, and $0.15 \%$ ethanol.

\section{Cell cultures}

Human trabecular osteoblasts ( $H O B$ ). Cells derived from human trabecular bone are felt to represent the differentiated osteoblasts that line bone surfaces (3). HOB were prepared according to the method of Gehron-Robey and Termine (22), with modifications (23). The trabecular bone obtained from human specimens as described above was minced and washed several times in DME/Ham's F-12 (1:1). The bone chips thus obtained were incubated with type IV collagenase (Sigma Chemical Co.) for $90 \mathrm{~min}$ at $37^{\circ} \mathrm{C}$ to release cells from the bone surfaces. The released cells were then seeded on plastic flasks, and cultured in the same medium, supplemented with $10 \%$ FCS, $100 \mu \mathrm{g} / \mathrm{ml}$ streptomycin, and $100 \mathrm{U} / \mathrm{ml}$ penicillin. The bone chips were washed in serum-containing medium to inhibit collagenase activity, and cultured separately using the same medium used for the collagenase-released cells. After a few days, cells migrated from within the bone particles and began to multiply; and within 3-4 wk they reached confluence. Thereafter, both collagenase-released cells and those outgrown from the bone chips were released with trypsin-EDTA $(0.05-0.02 \%$, respectively, Sigma Chemical Co.), counted, and subcultured in medium containing $10 \%$ FBS.

HOB are large cells that possess several cytoplasmic processes which typically extend up to $50-60 \mu \mathrm{m}$ (Fig. $1 \mathrm{~A}$ ). These processes allow cell-cell contact at a distance from the cell body. As demonstrated in Fig. $1 A$, HOB stain for alkaline phosphatase. Although most cells show specific staining, not all cells show the same degree of staining. This variability may reflect the heterogeneity within the population of osteoblastic cells. HOB produce osteocalcin both constitutively and under stimulation with $1,25(\mathrm{OH})_{2} \mathrm{D}_{3}(23)$. These features are characteristics of a differentiated osteoblastic phenotype (3).

Bone marrow osteogenic stromal cells (BMC). BMC are derived from human bone marrow, and are believed to represent less differentiated osteoblast precursors (24). BMC were isolated and cultured using a modification of the methods described by Ashton et al. (25), and Long et al. (26). Surgical specimens of ribs were obtained from voluntary donors undergoing chest surgery for various medical problems. The bone explants were split longitudinally and the bone marrow was collected by gently vortexing in serum-free DME/Ham's F-12 (1:1). The extract was mixed with an equal part of $\alpha \mathrm{MEM}$, and the mixture layered onto a discontinuous Ficoll-hypaque gradient. The mononuclear cell population was recovered from the upper level interface between the medium and the higher density Ficoll-hypaque, washed twice in $\alpha \mathrm{MEM}$, resuspended in the same medium, and seeded in tissue culture flasks or onto glass coverslips. The cultures were incubated in $\alpha \mathrm{MEM}$, supplemented with 5\% heat-inactivated FCS, and $100 \mu \mathrm{g} / \mathrm{ml}$ streptomycin and $100 \mathrm{U} / \mathrm{ml}$ penicillin.

As evident in Fig. $1 B$, only a small number of BMC cells exhibit alkaline phosphatase staining, suggestive of a less differentiated phenotype. Further differentiation of stromal cells toward an osteoblastic phenotype can be induced by incubation with dexamethasone (24). Therefore, some BMC cultures were incubated in $10^{-7} \mathrm{M}$ dexamethasone for at least $7 \mathrm{~d}$. At this time the cells appear larger and more flattened, and possess numerous short cytoplasmic processes. These morphologic features resemble those of the more differentiated trabecular bone-derived cells (see above). In addition, cells incubated with dexamethasone also express higher levels of alkaline phosphatase (Fig. $1 \mathrm{C}$ ), and produce greater amounts of osteocalcin, both constitutively
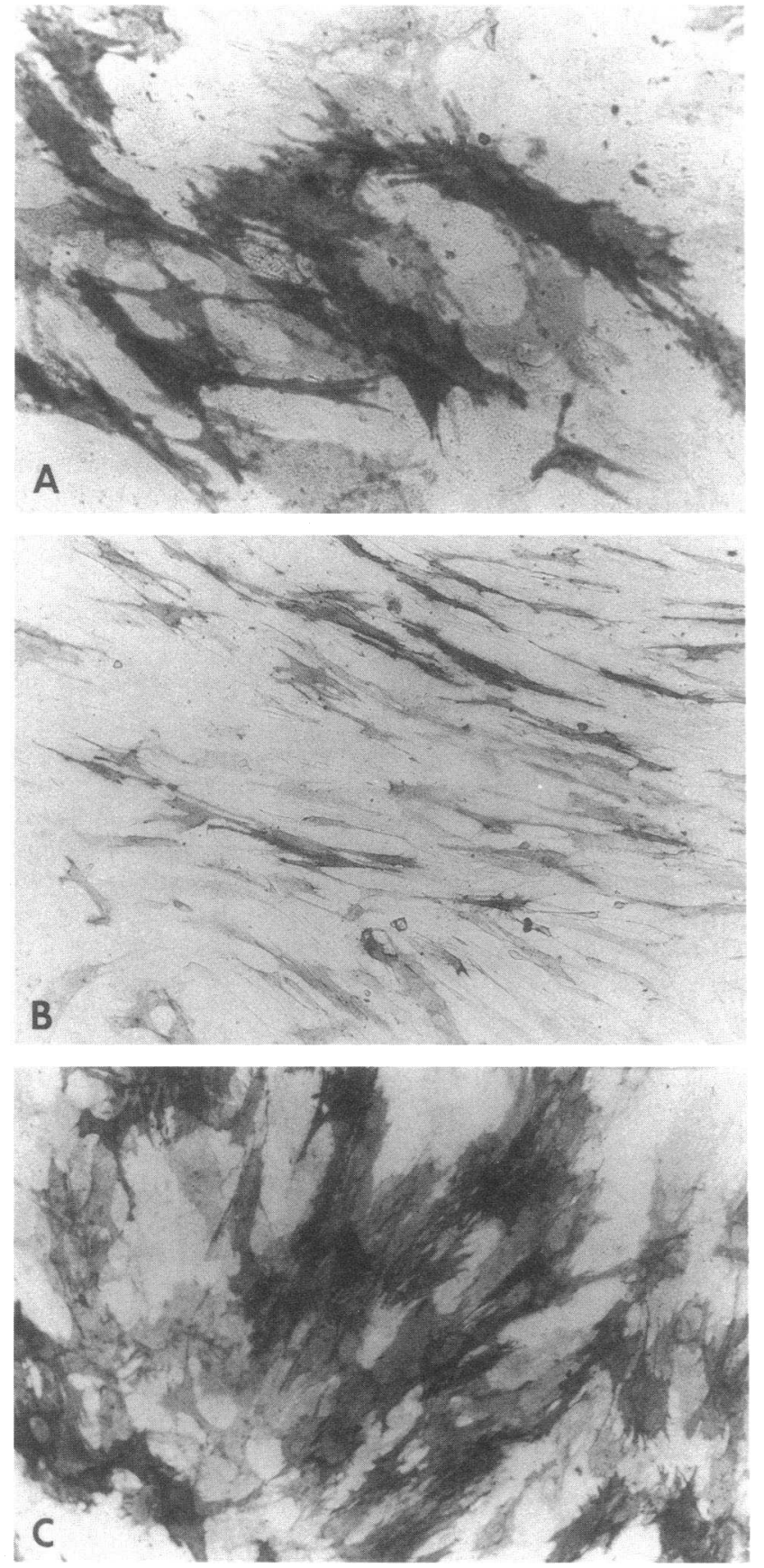

Figure 1. Phase contrast micrograph of alkaline phosphatase-stained human osteoblasts (HOB, $A$ ), bone marrow stromal cells (BMC) after a 7-d incubation without $(B)$, or with $10^{-7} \mathrm{M}$ dexamethasone $(C)$.

and under stimulation, than stromal cells grown in the absence of dexamethasone (24).

Osteogenic sarcoma cells. The clonal cell line SaOS- 2 was obtained from the American Type Culture Collection (Rockville, MD). These cells are derived from a human osteogenic sarcoma, and characterized as having an osteoblastic phenotype $(27,28)$. They were maintained in DME/Ham's F-12 (1:1), supplemented with 10\% FBS, as described (29).

\section{Dye coupling}

Gap junction communication was studied by intercellular diffusion of Lucifer yellow (30). Cells were subcultured on glass coverslips (31-mm diameter), and grown to $80 \%$ confluence. The coverslips were 
mounted on a thermostatted tissue chamber (Biophysica Technology, Baltimore, MD), covered with growth medium, and placed on the stage of an inverted epifluorescence microscope (Diaphot; Nikon, Garden City, NY), immediately before the microinjections. Borosilicate glass capillaries (outer diameter $1.2 \mathrm{~mm}$ ), with an internal glass fiber (Omega Dot; Stoelting Co., Wood Dale, IL) were used to pull micropipettes. Lucifer yellow ( $10 \mathrm{mM})$ was introduced into the capillaries by backfilling. Individual cells (six to eight per coverslip) were selected from within confluent areas, and microinjected $(1,100-1,200 \mathrm{hPa}$ for $0.3 \mathrm{~s}$ ) using a Zeiss-Eppendorf microinjector-micromanipulator (type 5242; Eppendorf, Hamburg, Germany), attached to the microscope stage. The volume of injected material did not cause any morphological changes of microinjected cells, as detected by light microscopy with phase contrast.

Lucifer yellow was excited using a microspectrofluorometric system (CM111I; Spex Industries, Edison, NJ), whose monochromator was set at $435 \mathrm{~nm}$. The excitation light was directed to the cell cultures by a dichroic mirror with 455 -nm cut-off wavelength. The light emitted by Lucifer yellow was filtered through a $460-\mathrm{nm}$ barrier filter, with 10-nm bandpass (BV-1A assembly cube; Nikon). Lucifer yellowemitted fluorescence was monitored using a low light silicon intensified target camera (SIT-66; Dage MTI, Michigan City, IN) connected to the lateral port of the microscope. Fluorescence images were displayed on a monitor, and recorded onto videotapes. Before the microinjection, a snapshot of the selected field under phase contrast illumination was also recorded. To avoid photobleaching of Lucifer yellow, the excitation light was directed to the sample only for a few seconds at different times during the experiment. The number of cells adjacent to each injection site exhibiting fluorescence 3-5 min after the injection was recorded. In some experiments, photographic images were taken by replacing the video camera with a photographic camera. Results obtained in a number of separate coverslips for each cell type and condition, were pooled. Quantitative analysis of cell coupling was performed by calculating the frequency distribution of the number of cells coupled to each single cell microinjected with Lucifer yellow, and normalizing the results to $100 \%$.

\section{RNA blots}

RNA blots were performed as previously described (19). Cells were grown to confluence in 100-mm plastic dishes, and total cellular RNA was isolated using guanidinium isothiocyanate (31). Samples (10 $\mu \mathrm{g}$ / lane) were separated on formaldehyde agarose gels and transferred to nylon membranes. The membranes were hybridized $(0.75 \mathrm{M}$ sodium phosphate, $1.0 \%$ SDS, $100 \mu \mathrm{g} / \mathrm{ml}$ salmon sperm DNA, $\left.65^{\circ} \mathrm{C}\right)$ and washed under high stringency conditions ( $30 \mathrm{mM}$ sodium phosphate, $1.0 \% \mathrm{SDS}, 65^{\circ} \mathrm{C}$ ). The following ${ }^{32} \mathrm{P}$-labeled cDNA probes were used: rat connexin26 (32), connexin 32 (33), connexin37 (34), connexin 40 (35), connexin43 (36), connexin45 (20), and connexin46 (37). A cDNA for human fibroblast $\boldsymbol{\gamma}$-actin was a gift of Dr. Stanley Korsmeyer, Washington University, St. Louis.

\section{Immunoprecipitation of connexin 43}

Cells were cultured on $100-\mathrm{mm}$ tissue culture plates to $75-85 \%$ confluence, incubated in methionine-free medium for $30 \mathrm{~min}$, and metabolically labeled with $300-\mu \mathrm{Ci} /$ plate $\left[{ }^{35} \mathrm{~S}\right]$ trans-S (ICN Biomedicals) for $6 \mathrm{~h}$. Cells were then washed and solubilized in $150 \mathrm{mM} \mathrm{NaCl}, 1 \%$ Triton X-100, $0.5 \%$ deoxycholate, $0.1 \%$ SDS, $0.5 \%$ BSA, $50 \mathrm{mM}$ Tris pH 8. Radioactivity was measured in a 5- $\mu$ l aliquot of each solubilized cell sample, and appropriate dilutions were made to achieve a uniform concentration of radiolabeled proteins before the samples were immunoprecipitated. Samples were vortexed, incubated $5 \mathrm{~min}$ at room temperature, vortexed again, and centrifuged at $12,000 \mathrm{rpm}$ for $5 \mathrm{~min}$ at $4^{\circ} \mathrm{C}$. Supernatants containing solubilized proteins were divided into aliquots and incubated overnight with either preimmune or anticonnexin 43 immune serum at $4^{\circ} \mathrm{C}$. The immune complexes were precipitated using protein A-Sepharose (Sigma Chemical Co.), and boiled in Laemmli sample buffer for $10 \mathrm{~min}$. Proteins were separated by electro- phoresis on $10 \%$ polyacrylamide gels with Promega Corp. (Madison, WI) mid-molecular weight protein standards. Gels were stained with Coomassie blue R-250, dried, and exposed to XAR-5 radiographic film.

\section{Immunofluorescence}

Cells grown on glass coverslips were fixed in methanol/acetone (1:1) for $2 \mathrm{~min}$ at room temperature, washed, and incubated in PBS containing $2 \%$ heat-inactivated goat serum and $1 \%$ Triton X-100 for $10 \mathrm{~min}$. The samples were incubated with a 1:200 dilution of either preimmune serum or anticonnexin serum for $\mathbf{4 5} \mathrm{min}$ at room temperature. After three washes in PBS, a 1:500 dilution of rhodamine-conjugated goat anti-rabbit IgG (Boehringer Mannheim Biochemicals, Indianapolis, IN) was added for $45 \mathrm{~min}$ at room temperature. The coverslips were washed twice in PBS, mounted on glass slides with glycerol/PBS (90/ 10 ), and sealed with nail polish. The epifluorescence photomicrographs were taken with a Zeiss Axioskop microscope.

\section{Results}

Dye coupling in human osteoblasts. Diffusion of Lucifer yellow between osteoblastic cells was used to assess gap junctional communication. As illustrated in Fig. 2, both HOB and BMC demonstrated a high degree of cell coupling, whereas the osteogenic sarcoma SaOS-2 cells were poorly coupled. Dye diffusion primarily occurred between two cell bodies, although occasionally the area of contact between two cells was small, suggestive of contact via a cytoplasmic process.

A quantitative analysis of cell coupling in $\mathrm{HOB}, \mathrm{SaOS}-2$, $\mathrm{BMC}$, and in BMC cultures treated with dexamethasone is shown in Fig. 3. About $80 \%$ of the HOB were found to be functionally coupled to other cells, with an average of $3.4 \pm 2.8$ $(n=131)$, and a rather wide scatter of the frequency distribution. Despite the high degree of coupling observed in some HOB (dye diffusion to $>10$ cells from a single cell), $\sim 20 \%$ of the HOB were not coupled. This variability was not dependent on the cell isolate or donor: variable results were obtained in monolayers derived from the same donor.

The number of coupled cells was higher in the stromal cells than in trabecular bone osteoblasts (Fig. 3). The average coupling for BMC in resting conditions was 8.1 $\pm 9.3(n=51)$, with one coupled cell per injected cell as the mode. BMC grown in the presence of dexamethasone exhibited a narrower range and lower average $(4.9 \pm 3.7 ; n=74)$ of coupled cells per cell, than those observed in cultures grown in the absence of the steroid. However, the mode was the same, and the two frequency distributions were not significantly different (Kolmogorov-Smirnov test).

In contrast, the transformed osteogenic sarcoma SaOS-2 cells were poorly coupled. No diffusion of Lucifer yellow occurred from $40 \%$ of microinjected cells, and the average coupling was only $1.4 \pm 1.8(n=100)$ coupled cells per cell. In addition, dye diffusion in the SaOS-2 line was slower than in any other cell type. While for HOB and BMC cells the spreading of Lucifer yellow was complete within 3-5 min from the microinjection, in the transformed cell line it required at least 10-12 min to reach maximal propagation, in the cases where diffusion occurred at all.

Effect of octanol on intercellular communication. We next performed microinjections in the presence of $3.8 \mathrm{mM}$ octanol, an inhibitor of junctional conductance $(38,39)$. We first analyzed the time-course of octanol effect on cell coupling. As 

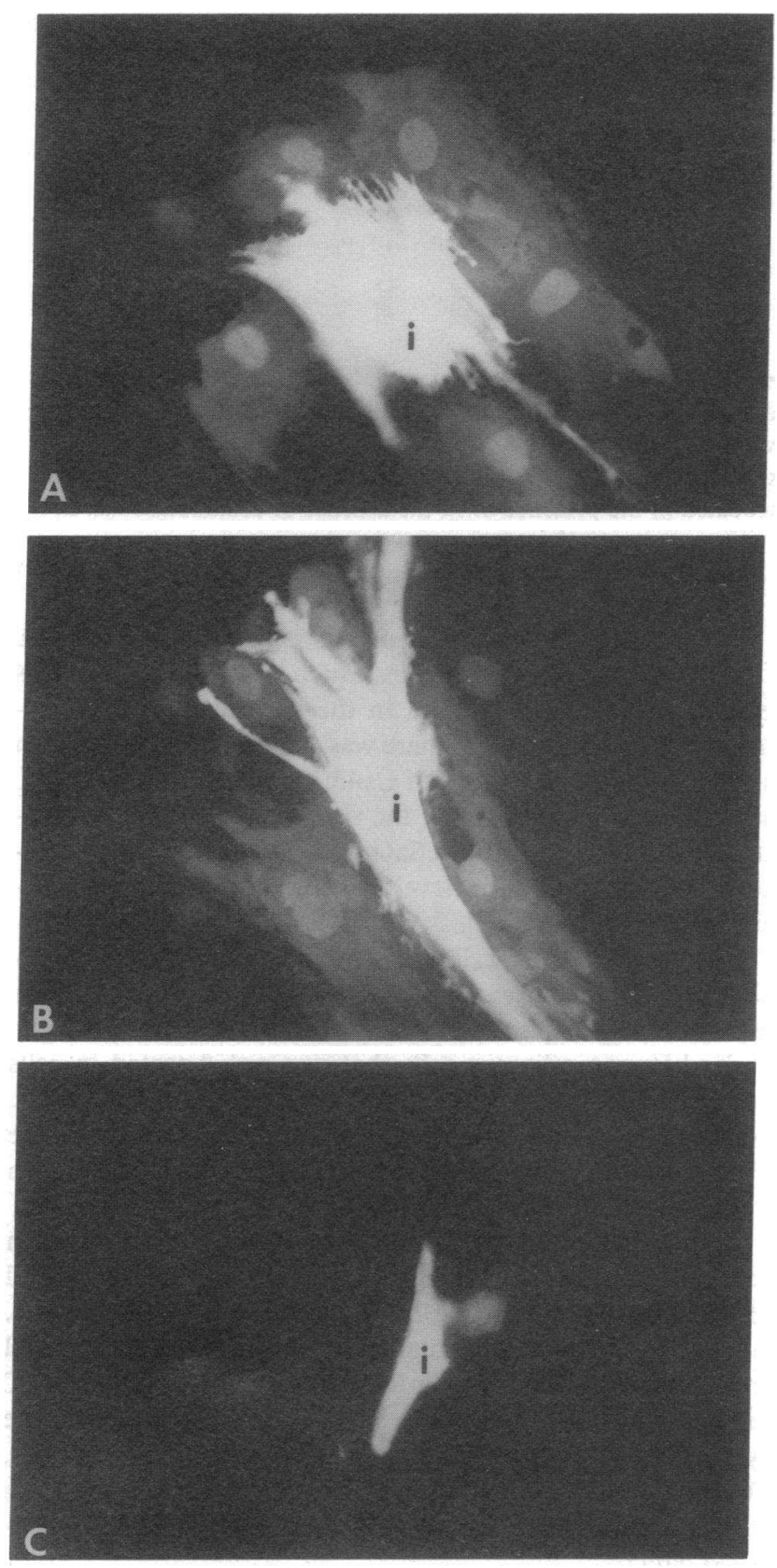

Figure 2. Diffusion of Lucifer yellow between human trabecular osteoblasts (HOB; $A$ ), stromal bone marrow cells (BMC; $B$ ), and SaOS-2 cells $(C)$. Cells grown on glass coverslips were microinjected with Lucifer yellow, and observed under fluorescence illumination (435-nm excitation, 455-465-nm emission). Micrographs were taken 5-10 min after microinjection of the dye. The cell microinjected in each micrograph is indicated by the letter $i$.

illustrated in Fig. 4, the inhibitory action of the alcohol was complete for $\sim 25-30$ min of incubation. Thereafter, the cells progressively regained their ability to transfer dye. On this basis, dye coupling was examined in both trabecular and bone marrow-derived osteoblasts within 20 min of exposure to octanol. In the presence of octanol, the number of coupled cells per injection was significantly reduced in all cases, with averages of 1.4 $\pm 2.0, n=23$ for HOB; 3.7 $\pm 5.0, n=11$ for BMC; and
1.8 $\pm 3.0, n=28$ for BMC grown in the presence of dexamethasone.

Expression of connexin43 in human osteoblasts. To identify the proteins that mediate gap junctional communication between osteoblasts, we asked whether any of the known members of the connexin family of gap junction proteins was expressed by these cells. We isolated total cellular RNA from the osteoblasts, and performed RNA blots using ${ }^{32} \mathrm{P}$-labeled cDNA probes for $\mathrm{Cx} 26, \mathrm{Cx} 32, \mathrm{Cx} 37, \mathrm{Cx} 40, \mathrm{Cx} 43, \mathrm{Cx} 45$, and $\mathrm{Cx} 46$. BMC, HOB, and SaOS-2, all expressed mRNA for $\mathrm{Cx} 43$ and $\mathrm{Cx} 45$ (see below), but not for Cx26, Cx32, Cx37, Cx40 or Cx46 (not shown).

RNA isolated from all of the human osteoblastic cells contained a band that hybridized with the rat $\mathrm{Cx} 43 \mathrm{cDNA}$ probe, and this band was the same size as that of the control RNA isolated from rat heart (Fig. 5). Although BMC and HOB were more highly coupled than the SaOS-2 cells, all of the osteoblastic cells contained similar quantities of $\mathrm{Cx} 43$ RNA. To confirm the integrity of the mRNA present on these blots, membranes were reported with an action cDNA probe; actin bands of similar density were detected in each sample (data not shown).

The expression of $\mathrm{Cx} 43$ protein in the normal and trans-

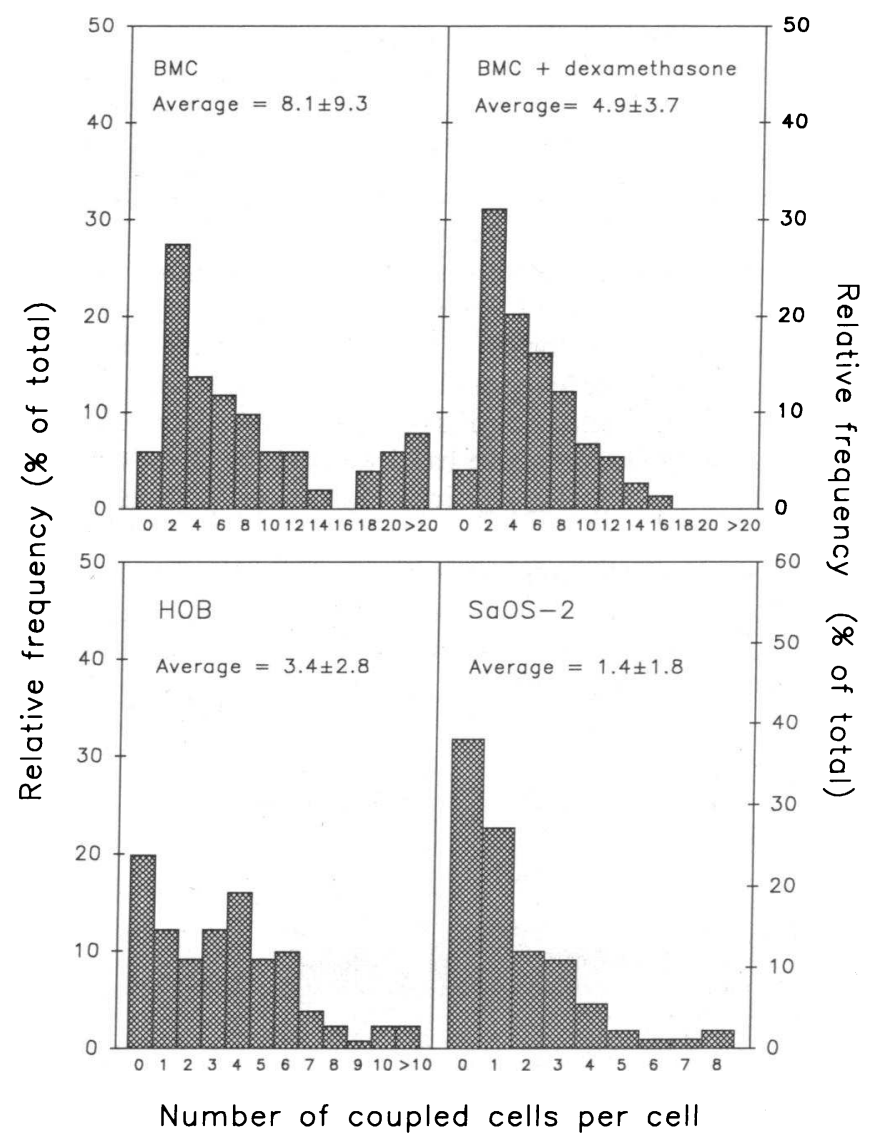

Figure 3. Cell coupling in human osteoblasic cells. Cells grown on glass coverslips were prepared as described in Methods, and microinjected with Lucifer yellow. The number of cells coupled to each cell microinjected was determined either 3-5 min (HOB and BMC) or 10-12 min (SaOS-2) after microinjection. Data for each cell type were pooled from different experiments performed in different coverslips (3-10 microinjections per coverslip), and were normalized to $100 \%$ to allow comparisons among groups. 


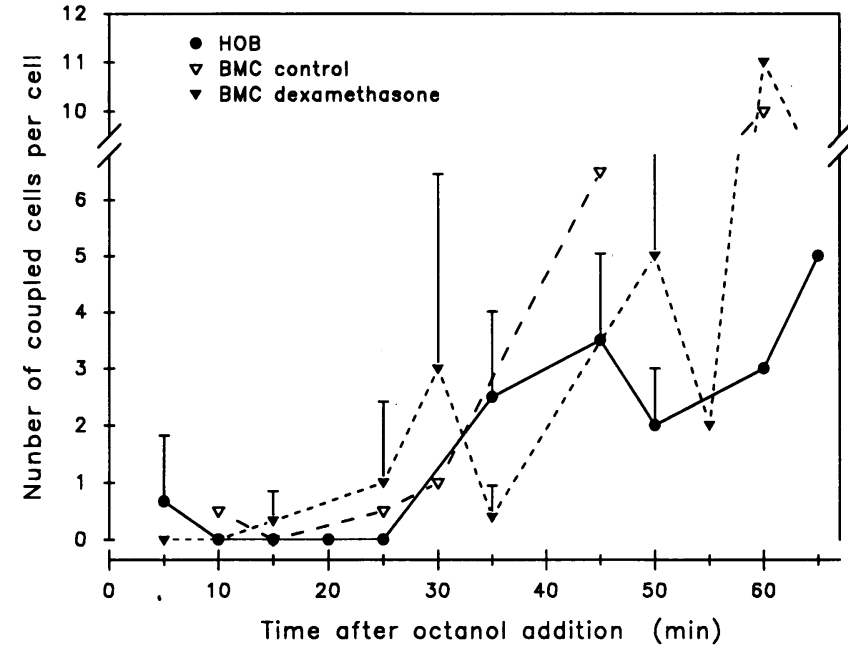

Figure 4. Time-course of octanol inhibition of cell coupling. Human osteoblastic cells grown on glass coverslips were microinjected with Lucifer yellow. The number of cells coupled to a single cell microinjected with the fluorescent probe was recorded at the different time points. Only one microinjection per coverslip was performed in these experiments, to ensure exact timing. Between two and five cells were studied for each time point. Data represent the average and standard deviations, when applicable.

formed osteoblastic cells was assessed by immunoprecipitation after metabolic labeling with $\left[{ }^{35} \mathrm{~S}\right]$ methionine. $\mathrm{Cx} 43$ was precipitated from all the cell types (Fig. 6). In HOB and BMC cultures, labeled protein bands of $\sim 40$ and $42 \mathrm{kD}$ were precipitated with immune serum but not with preimmune serum. These bands correspond, respectively, to nonphosphorylated and phosphorylated forms of $\mathrm{Cx} 43$, as demonstrated by the presence of only the lower molecular mass form of the protein in phosphatase-treated samples (data not shown, and reference 21). A 43-kD cross-reactive band was present in precipitates using both preimmune and immune serum. Its presence in immunoprecipitates performed in the presence of $100 \mu \mathrm{g} / \mathrm{ml}$ of the immunizing peptide demonstrates that this band is not a Cx43-specific band (19). Treatment with dexamethasone did not significantly affect the expression of $\mathrm{Cx} 43$ protein by BMC cells (Fig. 6, right panel).

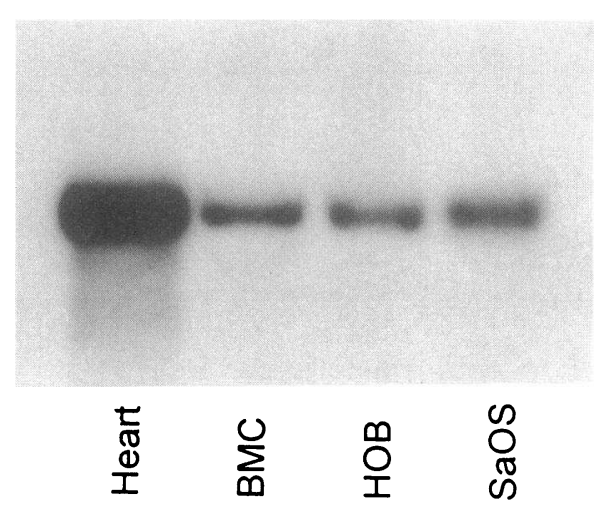

Figure 5. Expression of connexin 43 mRNA by human osteoblasts. Total RNA was isolated from nearly confluent cultures of BMC, $\mathrm{HOB}$, and SaOS-2 cells, and formaldehyde-agarose gels were run using $10 \mu \mathrm{g}$ of sample for each cell type. Rat heart RNA was used as a control.

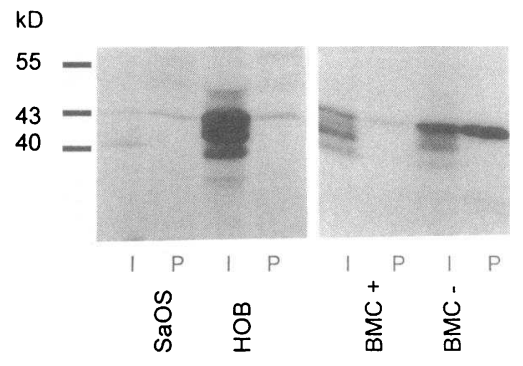

Figure 6. Expression of connexin 43 protein by human osteoblasts. Cells were grown to confluence in tissue culture dishes, solubilized, and immunoprecipitated with anti-Cx43 serum or preimmune serum. In HOB and BMC cells, Cx43 appeared as two bands that migrated at 40 and $42 \mathrm{kD}$, representing nonphosphorylated and phosphorylated forms of the protein, respectively. The blot on the left panel showing HOB and SaOS- 2 cells was exposed twice as long as the blot in the right panel, showing BMC cells incubated in the presence or in the absence of dexamethasone. $P$, preimmune serum; $I$, immune serum.

In contrast with the equivalent expression of $\mathrm{Cx} 43 \mathrm{mRNA}$ in $\mathrm{HOB}, \mathrm{BMC}$, and $\mathrm{SaOS}-2$ cells, much less $\mathrm{Cx} 43$ protein was detected in SaOS-2 cells than in the nontransformed osteoblasts (Fig. 6). In addition, there was a consistent difference in the state of phosphorylation of $\mathrm{Cx} 43$ : while in $\mathrm{HOB}$ and $\mathrm{BMC}$ the major $\mathrm{Cx} 43$ band was of the slower mobility phosphorylated form of the protein, in SaOS-2 cells most of the precipitated Cx43 migrated at the level of the nonphosphorylated protein.

We also studied the cellular distribution of connexin 43 protein by immunofluorescence. Both the HOB and BMC cells displayed a linear punctate distribution of fluorescence at the border between adjacent cells that was not detected in cells incubated with preimmune serum (Fig. 7). In SaOS-2 cells, specific $\mathrm{Cx} 43$ staining was also seen at the plasma membrane (Fig. 8, $a$ and $b$ ), although it was much less abundant than in nontransformed cells.

Expression of CX45 in human osteoblastic cells. Under high stringency conditions, a dog Cx45 cDNA probe hybridized with RNA isolated from the human osteoblastic cells (Fig. 9). In contrast to the results obtained with $\mathrm{Cx} 43$, the $\mathrm{SaOS}-2$ cell line expressed more $\mathrm{Cx} 45 \mathrm{mRNA}$ than did HOB and BMC cultures. The $\mathrm{Cx} 45$ band migrated more slowly than did the hybridizing band detected in the control rat uterus RNA (Fig. 9), but at the same level as the hybridizing band detected in human heart RNA (Kanter, H.L., and E.C. Beyer, unpublished data).

Immunofluorescence studies using an antibody directed against a cytoplasmic sequence of $\mathrm{Cx} 45$ demonstrated that in SaOS- 2 cells, $\mathrm{Cx} 45$ was located on the plasma membrane between adjacent cells (Fig. 8, $c$ and $d$ ). Specific $\mathrm{Cx} 45$ staining was not observed in HOB, or in BMC cultures (not shown), consistent with the low level of $\mathrm{Cx} 45 \mathrm{mRNA}$ detected in these cells.

\section{Discussion}

This study establishes the presence of functional gap junctions in human osteoblastic cells. The level of expression of Cx43 protein in human osteoblasts correlates with the degree of cellcell coupling. Therefore, these data provide strong evidence that connexin 43 is the protein that is responsible for gap junction formation and intercellular dye coupling in osteoblasts. 

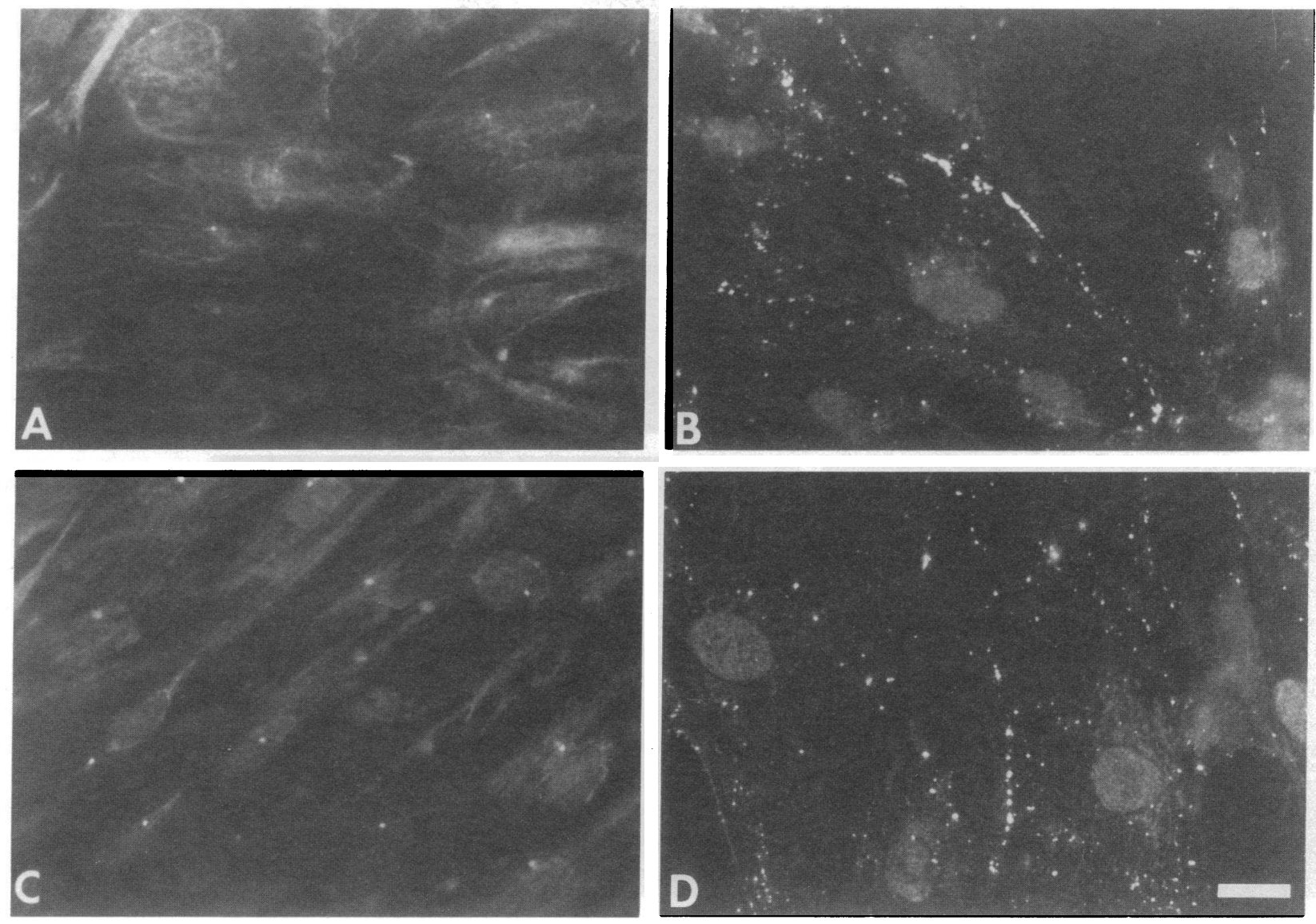

Figure 7. Immunofluorescence staining for connexin 43 in human osteoblastic cells. Human trabecular bone osteoblasts (HOB; $A$ and $B$ ), and bone marrow stromal cells (BMC; $C$ and $D$ ) were grown on glass coverslips, fixed, and incubated with either preimmune serum $(A$ and $C$ ), or anti-Cx43 serum ( $B$ and $D$ ), followed by rhodamine-conjugated goat anti-rabbit IgG antibody. Bar $=20 \mu \mathrm{m}$.

Gap junctions form conduits between cells, thereby establishing intercellular electrical and chemical coupling. The function of gap junctions in cardiac muscle seems relatively clear, since electrical impulses must be transmitted rapidly for the heart to function as an effective pump. In other tissues, where the need for electrical coupling is not evident, the physiologic role of gap junctions is less clear.

The skeletal tissue presents several interesting features in terms of the potential roles for gap junction proteins. The main physiologic processes, bone resorption and formation, are enacted by specific but strictly cooperating cell types, osteoclasts and osteoblasts, respectively. Close interaction between these cell types occurs during the complex bone remodeling process, a phenomenon called "coupling" (40). Although remarkable efforts have been expended in the identification of potential soluble factors that may mediate osteoblast-osteoclast coupling, the possibility of direct cell-cell communication in bone has been given little attention. A few morphologic studies are available demonstrating the existence of gap junctions between adjacent osteoblasts, osteoblasts and osteocytes and osteocytic processes (13-15), and in cultures of rat calvaria cells (16).

Communication between osteoblasts and osteocytes through cytosolic processes may be involved in skeletal growth regulation. Since osteocytes are completely embedded within the calcified bone, they are in an optimal position to sense and transduce mechanical forces that are applied to the skeleton.
Gap junctions on the cytosolic process may allow the osteocytes to transmit these signals to the cells on the endosteal and periosteal surface, and therefore direct the architectural development of the skeleton. Indeed, stretch-activated ion channels have been identified on the plasma membrane of bone cells (41), and, more recently, propagation of $\mathrm{Ca}^{2+}$ signal through osteoblastic monolayers has been demonstrated to occur after mechanical stimulation (42).

Gap junctional communication may also allow the osteoblasts lining the bone surface to work in synchrony during the production and deposition of organic matrix and subsequent calcification. Thus, one could speculate that osteoblasts operating within a bone remodeling unit $(3,43)$ may be functionally interdependent via direct cell-cell contacts, which would provide the mechanism for a coordinated action within each single unit. Osteoblasts are also able to establish chemical coupling with neighboring cells in their environment at any time during their differentiation. As demonstrated by morphologic studies (13-15), heterotypic coupling is possible, thus allowing the osteoblasts to exchange signals with cells on the bone surface.

Analysis of intercellular relationships between bone cells is difficult because of the structural complexity of this tissue. However, the different cell models employed in this study allow some initial extrapolations to the possible role of gap junctions in osteoblasts. These cells undergo a relatively long differentiation process from osteogenic stromal cells of the bone 

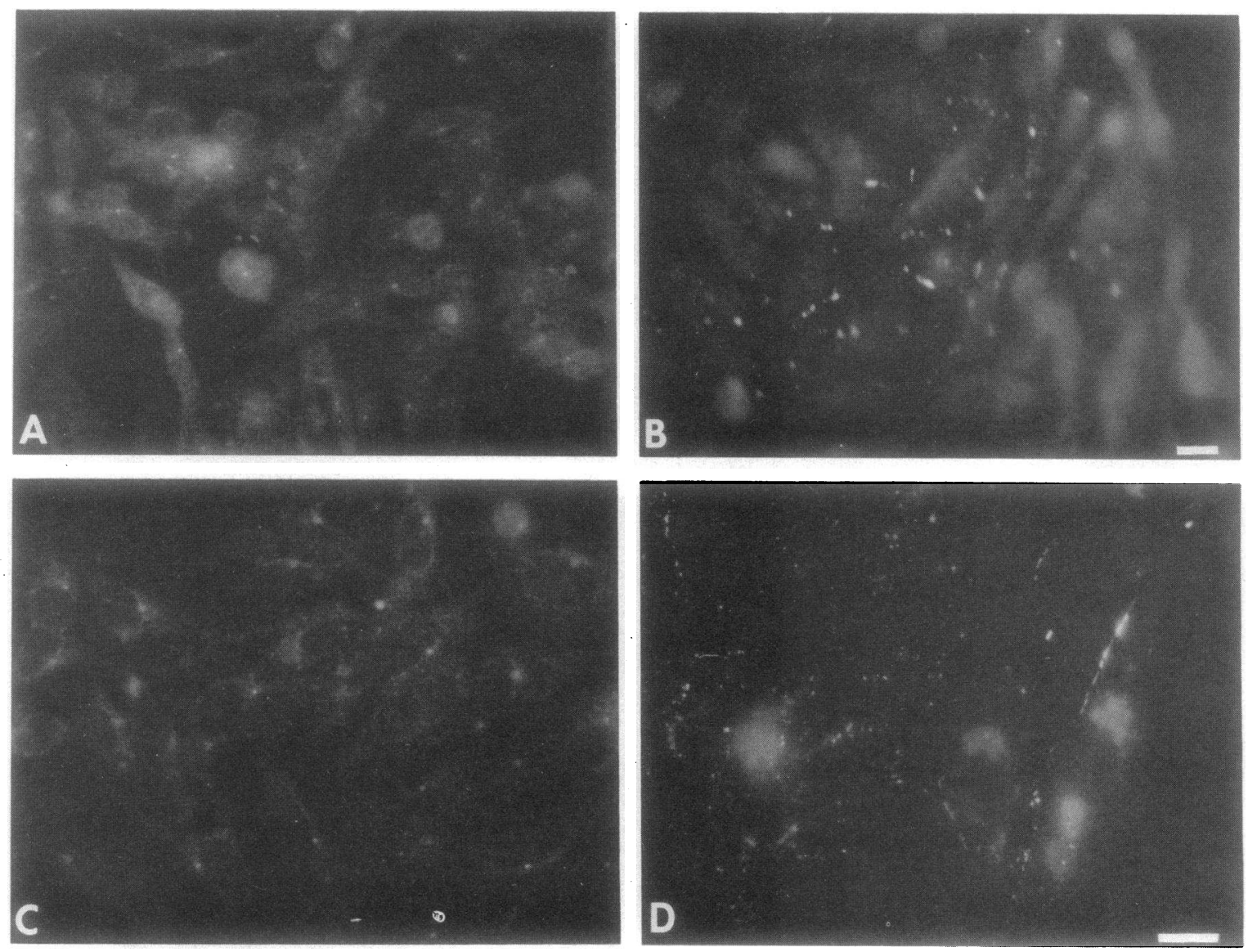

Figure 8. Immunofluorescence localization of connexin 43 and connexin 45 in SaOS-2 cells. Adherent SaOS-2 cells were fixed and stained for either $\mathrm{Cx} 43(A$ and $B)$ or $\mathrm{Cx} 45$ ( $C$ and $D)$, followed by rhodamine-conjugated goat anti-rabbit IgG secondary antibody. $(A$ and $C)$ preimmune serum; $(B$ and $D)$ immune serum. Bar $=20 \mu \mathrm{m}$.

marrow to differentiated osteoblasts lining the bone surfaces. Subsequently, some of the osteoblasts in actively forming bone remain embedded within the calcified tissue and become osteocytes, the terminal differentiation step along the osteoblastic lineage (3). In our studies, both the stromal BMC, probably representing an early stage of differentiation, and the more differentiated $\mathrm{HOB}$, derived from cells residing on the bone surfaces, demonstrated a high degree of dye-coupling and expression of connexin43. Further differentiation of BMC by incubation with dexamethasone was not associated with significant

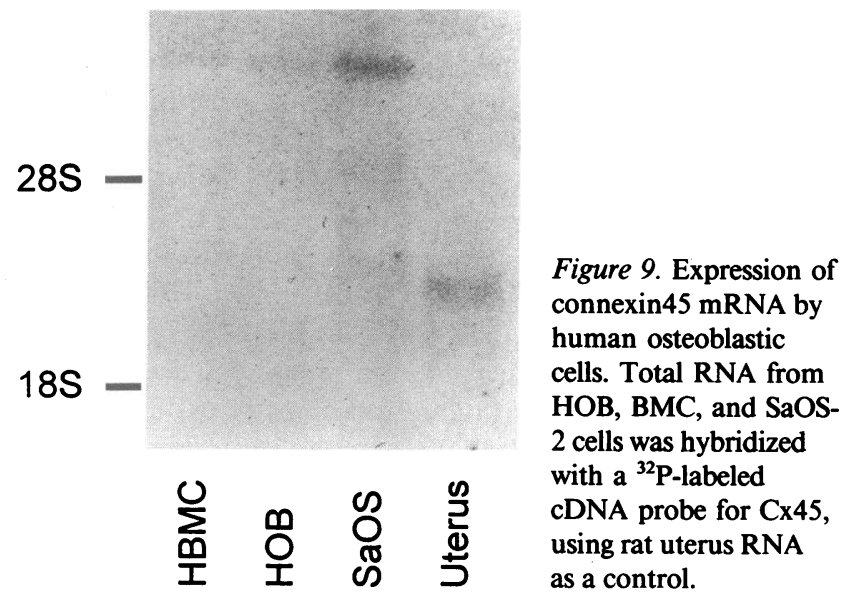

inhibition of dye-coupling and Cx43 expression. Therefore, our data seem to indicate that the presence of functionally active gap junctions is not dependent on any particular phase of osteoblast differentiation. However, it is possible that gap junctional conductance, and/or $\mathrm{Cx} 43$ production and assembly into connexons may be differentially regulated at each stage of differentiation, perhaps reflecting different functional requirements for gap junctional communication.

This work demonstrates that $\mathrm{Cx} 43$ is the major gap junction protein expressed by human osteoblasts, and that expression of $\mathrm{Cx} 43$ is correlated with the degree of cell coupling. These results are consistent with a recent studies in rat calvaria cells (17), and in rat osteogenic sarcoma cells (ref. 18, and Steinberg, T. H., R. Civitelli, et al., manuscript in preparation ), all pointing to $\mathrm{Cx} 43$ as the gap junction protein responsible for cell-cell communication between osteoblastic cells. Connexin 43 was first isolated from heart tissue (36), but it has been later identified in a number of other cell types, including kidney, brain, ovary, smooth muscle, and some epithelia (21, 44 ). The accumulated data on osteoblasts provide further evidence that expression of this gap junction protein is widespread.

Connexin 43 mRNA and protein were also expressed by the poorly coupled osteogenic sarcoma cells SaOS-2. Although these cells expressed as much Cx43 mRNA as the well-coupled nontransformed HOB and BMC, SaOS-2 expressed much less Cx43 protein, as demonstrated by immunoprecipitation and 
immunofluorescence. Although the reason for the dissociation between mRNA and protein expression in these cells is unknown, the relatively low $\mathrm{Cx} 43$ protein expression is commensurate to the degree of dye-coupling exhibited by the SaOS-2 cells compared to the normal osteoblastic cells. This is perhaps the consequence of an abnormal pattern of oncogene expression characteristic of tumoral cells, and which may inhibit the production of gap junction proteins, as demonstrated to occur in cells expressing v-ras or v-src (45-47). Alternatively, SaOS2 cells may lack an adhesion protein required for cell coupling. The lack of $\mathrm{Cx} 43$ phosphorylation in the SaOS cells is reminiscent of the findings of Musil et al. (48) in the S180 sarcoma line. These cells appeared to be deficient in the expression of adhesion proteins; transfection of the cells with E-cadherin resulted in $\mathrm{Cx} 43$ phosphorylation and intercellular communication.

Interestingly, the SaOS-2 cells expressed higher amounts of Cx45 mRNA than did the HOB or BMC. Thus, the expression of $\mathrm{Cx} 45$ inversely correlated with dye coupling in these cells, in spite of the fact that in SaOS- 2 cells $\mathrm{Cx} 45$ was shown by immunofluorescence to be localized to the plasma membrane, in a pattern characteristic of functional gap junctions. These observations suggest that in human osteoblastic cells $\mathrm{Cx} 45$ may not be functional, at least in the conditions used for these experiments. This consideration, coupled to the very low expression of $\mathrm{Cx} 45$ by $\mathrm{HOB}$ and $\mathrm{BMC}$, suggests that $\mathrm{Cx} 45$ does not play a major role in cell-cell communication between human osteoblasts.

In summary, the present work establishes that human osteoblasts are functionally interconnected by gap junctions, and that $\mathrm{Cx} 43$, the major gap junction protein expressed by these cells, mediates intercellular communication in these cells. The ability to exchange and diffuse nutrients and regulatory molecules throughout the bone environment may represent an efficient means of coordinating the action of a variety of cells in a highly complex tissue.

\section{Acknowledgments}

The authors are indebted to Su-Li Cheng, Leonard Rifas, and Linda R. Halstead for the human tissue cultures; to Elizabeth Hick for performing immunofluorescence studies; and to Michael Scott and Marilyn Roberts for technical assistance.

This work has been supported, in part, by National Institutes of Health grants AR-41255 (R. Civitelli), GM-45815 (T. H. Steinberg), and HL-45466 and EY-08368 (E. C. Beyer). E. C. Beyer and T. H. Steinberg are Established Investigators of the American Heart Association.

\section{References}

1. Marcus, R. 1987. Normal and abnormal bone remodeling in man. Annu. Rev. Med. 38:129-141.

2. Parfitt, A. M. 1988. Bone remodeling: relationship to the amount and structure of bone, and the pathogenesis and prevention of fractures. In Osteoporosis: Etiology, Diagnosis, and Management. B. L. Riggs and L. J. Melton, editors. Raven Press, Ltd., New York. 45-93.

3. Rodan, G. A., and L. G. Raisz. 1990. Cellular basis for bone turnover. In Metabolic Bone Diseases and Clinically Related Disorders. L. V. Avioli and S. M. Krane, editors. W. B. Saunders Co., Philadelphia. 1-41.

4. Rodan, G. A., and T. J. Martin. 1981. Role of osteoblasts in hormonal control of bone resorption-a hypothesis. Calcif. Tissue Int. 33:349-351.

5. Silve, C. M., G. T. Hradek, A. L. Jones, and C. T. Arnaud. 1982. Parathyroid hormone receptor in intact embryonic chicken bones: characterization and cellular localization. J. Cell Biol. 94:379-386.
6. Narbaitz, R., W. E. Stumpf, M. Sar, S. Huang, and H. F. DeLuca. 1983. Autoradiographic localization of target cells for 1,25-dihydroxyvitamin $D_{3}$ in bones from fetal rats. Calcif. Tissue Int. 35:177-182.

7. Juppner, H., A. B. Abou-Samra, S. Uneno, W.-X. Gu, J. T. Potts, Jr., and G. V. Segre. 1988. The parathroid hormone-like peptide associated with humoral hypercalcemia of malignancy and parathyroid hormone bind to the same receptor on the plasma membrane of ROS 17/2.8 cells. J. Biol. Chem. 263:85578560 .

8. McSheehy, P. M. J., and T. J. Chambers. 1986. Osteoblast-like cells in the presence of parathyroid hormone release soluble factor that stimulates osteoclastic bone resorption. Endocrinology. 119:1654-1659.

9. McSheehy, P. M. J., and T. J. Chambers. 1987. 1,25-dihydroxyvitamin $D_{3}$ stimulates rat osteoblastic cells to release a soluble factor that increases osteoclastic bone resorption. J. Clin. Invest. 80:425-429.

10. Morris, C. A., M. E. Mitnick, E. C. Weir, M. Horowitz, B. L. Kreider, and K. L. Insogna. 1990. The parathyroid hormone-related protein stimulates human osteoblast-like cells to secrete a 9,000 dalton bone-resorbing protein. Endocrinology. 126:1783-1785.

11. Thomson, B. M., G. R. Mundy, and T. J. Chanbers. 1987. Tumor necrosis factors $\alpha$ and $\beta$ induce osteoblastic cells to stimulate osteoclastic bone resorption. J. Immunol. 138:775-779.

12. Thomson, B. M., J. Saklatvala, and T. J. Chambers. 1986. Osteoblasts mediate interleukin-1 stimulation of bone resorption by rat osteoclasts. J. Exp. Med. 164:104-112.

13. Jeasonne, B. G., F. A. Faegin, R. W. McMinn, R. L. Shoemaker, and W. S. Rehm. 1979. Cell-to-cell communication of osteoblasts. J. Dent. Res. 58:14151419.

14. Doty, S. B. 1981. Morphological evidence of gap junctions between bone cells. Calcif. Tissue Int. 33:509-511.

15. Doty, S. B. 1988. Cell-to-cell communication in bone tissue. In The Biological Mechanisms of Tooth Eruption and Root Resorption. Z. Davidovitch, editor. EBSCO Media, Birmingham, AL. 61-69.

16. Shen, V., L. Rifas, G. Kohler, and W. A. Peck. 1986. Prostaglandins change cell shape and increase intercellular gap junctions in osteoblasts cultured from rat fetal calvaria. J. Bone Miner. Res. 1:243-249.

17. Schirrmacher, K., I. Schmitz, E. Winterhager, O. Traub, F. Brummer, D. Jones, and D. Bingmann. 1992. Characterization of gap junctions between osteoblast-like cells in culture. Calcif. Tissue Int. 51:285-290.

18. Schiller, P. C., P. P. Mehta, B. A. Roos, and G. A. Howard. 1992. Hormonal regulation of intercellular communication: parathyroid hormone increases connexin 43 gene expression and gap-junctional communication in osteoblastic cells. Mol. Endocrinol. 6:1433-1440.

19. Beyer, E. C., and T. H. Steinberg. 1991. Evidence that the gap junction protein connexin-43 is the ATP-induced pore of mouse macrophages. J. Biol. Chem. 266:7971-7974.

20. Kanter, H. L., J. E. Saffitz, and E. C. Beyer. 1992. Cardiac myocytes express multiple gap junction proteins. Circ. Res. 70:438-444.

21. Musil, L. S., E. C. Beyer, and D. A. Goodenough. 1990. Expression of the gap junction protein connexin43 in embryonic chick lens: molecular cloning, ultrastructural localization, biosynthesis, and post-translational phosphorylation. J. Membr. Biol. 116:163-175.

22. Gehron-Robey, P., and J. D. Termine. 1985. Human bone cells in vitro. Calcif. Tissue Int. 37:453-460.

23. Rifas, L., L. R. Halstead, W. A. Peck, L. V. Avioli, and H. G. Welgus. 1989. Human osteoblasts in vitro secrete tissue inhibitor of metalloproteinases and gelatinase but not interstitial collagenase as major cellular products. J. Clin. Invest. 84:686-694.

24. Cheng, S.-L., L. Rifas, J. Yang, and L. V. Avioli. 1991. Characterization of dexamethasone-induced human bone marrow stromal osteoblast-like cells. $J$. Bone Miner. Res. 6:S89.(Abstr.)

25. Ashton, B. A., F. Abdullah, J. Cave, M. Williamson, B. C. Sykes, M. Couch, and J. W. Poser. 1985. Characterization of cells with high alkaline phosphatase activity derived from human bone and marrow: preliminary assessment of their osteogenicity. Bone (Elmsford). 6:313-319.

26. Long, M. W., J. L. Williams, and K. G. Mann. 1990. Expression of human bone-related proteins in the hematopoietic microenvironment. J. Clin. Invest. 86:1387-1395.

27. Boland, C. J., R. M. Fried, and A. H. Tashijan, Jr. 1986. Measurement of cytosolic free $\mathrm{Ca}^{2+}$ concentrations in human and rat osteosarcoma cells: actions of bone resorption-stimulating hormones. Endocrinology. 118:980-989.

28. Shupnik, M. A., and A. H. Tashijan, Jr. 1982. Epidermal growth factor and phorbol ester action on human osteosarcoma cells: characterization of responsive and nonresponsive cell lines. J. Biol. Chem. 257:12161-12164.

29. Civitelli, R., Y. S. Kim, S. L. Gunsten, A. Fujimori, M. Huskey, L. V. Avioli, and K. A. Hruska. 1990. Nongenomic activation of the calcium message system by vitamin D metabolites in osteoblast-like cells. Endocrinology. 127:2253-2262.

30. Stewart, W. W. 1978. Functional connections between cells as revealed by dye-coupling with a highly fluorescent napthalimide tracer. Cell. 14:741-759. 
31. Chomczynski, P., and N. Sacchi. 1987. Single-step method of RNA isolation by acid guanidinium thiocyanate-phenol-chloroform extraction. Anal. Biochem. 162:156-159.

32. Zhang, J. T., and B. J. Nicholson. 1989. Sequence and tissue distribution of a second protein of hepatic gap junctions, $\mathrm{Cx} 26$, as deduced from its cDNA. $J$. Cell Biol. 109:3391-3401.

33. Paul, D. L. 1986. Molecular cloning of cDNA for rat liver gap junction protein. J. Cell Biol. 103:123-134.

34. Willecke, K., R. Heynkes, E. Dahl, R. Stutenkemper, H. Hennemann, S. Jungbluth, T. Suchyna, and B. J. Nicholson. 1991. Mouse connexin37: cloning and functional expression of a gap junction gene highly expressed in lung. J. Cell Biol. 114:1049-1057.

35. Beyer, E. C., K. E. Reed, E. M. Westphale, H. L. Kanter, and D. M Larson. 1992. Molecular cloning and expression of rat connexin40, a gap junction protein expressed in vascular smooth muscle. J. Membr. Biol. 127:69-76.

36. Beyer, E. C., D. L. Paul, and D. A. Goodenough. 1987. Connexin43: a protein from rat heart homologous to a gap junction protein from liver. $J$. Cell Biol. 105:2621-2629.

37. Paul, D. L., L. Ebihara, L. J. Takemoto, K. I. Swenson, and D. A. Goodenough. 1991. Connexin46, a novel lens gap junction protein, induces voltagegated currents in nonjunctional plasma membrane of Xenopus oocytes. J. Cell Biol. 115:1077-1089.

38. Burt, J. M., and D. C. Spray. 1988. Single-channel events and gating behavior of the cardiac gap junction channel. Proc. Natl. Acad. Sci. USA. 85:3431-3434.

39. Chanson, M., R. Bruzzone, D. Bosco, and P. Meda. 1989. Effects of $\mathrm{n}$-alcohols on junctional coupling and amylase secretion of pancreatic acinar cells. J. Cell. Physiol. 139:147-156.
40. Parfitt, A. M. 1982. The coupling of bone formation to bone resorption: a critical analysis of the concept and of its relevance to the pathogenesis of osteoporosis. Metab. Bone Dis. \& Relat. Res. 4:1-6.

41. Duncan, R. L., and S. Misler. 1989. Voltage-activated and stretch activated $\mathrm{Ba}^{2+}$-conducting channels in an osteoblast-like cell line (UMR 106-01). FEBS (Fed. Eur. Biochem. Soc.) Lett. 251:17-21.

42. Xia, S.-L., and J. Ferrier. 1992. Propagation of a calcium pulse between osteoblastic cells. Biochem. Biophys. Res. Commun. 186:1212-1219.

43. Frost, H. M. 1986. Intermediary Organization of the Skeleton. CRC Press, Inc., Boca Raton, FL.

44. Beyer, E. C., J. Kistler, D. L. Paul, and D. A. Goodenough. 1989. Antisera directed against connexin 43 peptides react with a $43-\mathrm{kD}$ protein localized to gap junctions in myocardium and other tissues. J. Cell Biol. 108:595-605.

45. Atkinson, M. M., and J. D. Sheridan. 1988. Altered junctional permeability between cells transformed by v-ras, v-mos, or v-src. Am. J. Physiol. 255:C674 C683.

46. Bignami, M., S. Rosa, G. Falcone, F. Tato, F. Katoh, and H. Yamasaki. 1988. Specific viral oncogenes cause differential effects on cell-to-cell communication, relevant to the suppression of the transformed phenotype by normal cells. Mol. Carcinog. 1:67-75.

47. Brissette, J. L., N. M. Kumar, N. B. Gilula, and G. P. Dotto. 1991. The tumor promoter 12-0-tetradecanoylphorbol-13-acetate and the ras oncogene modulate expression and phosphorylation of gap junction proteins. Mol. Cell. Biol. 11:5364-5371.

48. Musil, L. S., B. A. Cunningham, G. M. Edelman, and D. A. Goodenough. 1990. Differential phosphorylation of the gap junction protein connexin43 in junctional communication-competent and -deficient cell lines. J. Cell Biol. 111:2077-2088. 